\title{
Regeneration Potential of Immature Embryos during Seed Development in Spring and Winter Wheat Genotypes
}

\author{
Kyung-Hee Kim, Ji-Suk Park, and Byung-Moo Lee ${ }^{\dagger}$ \\ Department of Plant Biotechnology, Dongguk Univ.-Seoul, 100-715 Korea
}

\begin{abstract}
The immature embryos during seed development were examined to predict the suitable embryos for an efficient regeneration system. Five spring wheat genotypes and five winter wheat genotypes were tested using immature embryos as explants. Spring wheat genotypes showed much higher levels of plant regeneration than those of winter wheat genotypes. The highest frequencies of embryogenesis and regeneration were obtained when embryos at 13-14 days after anthesis (DAA) were used as explant and decreased using embryos at 21-22 DAA during seed development. Significant differences were also found for callus induction and regeneration as affected by immature embryo size. The regeneration efficiency was drastically decreased in spring and winter wheat genotypes when embryos larger than 2.0 $\mathrm{mm}$ of length were used. The optimum developmental stage and embryo length for regeneration efficiency were at 13-14 DAA and $1.0-1.5 \mathrm{~mm}$, respectively. The selection of suitable embryos for the high frequencies of embryogenesis and regeneration leads us to efficient genetic improvement of wheat.
\end{abstract}

Keywords : wheat, regeneration, seed development, immature embryo

Recent development in genetic manipulation of plant cell has opened new possibilities in crop improvement. Genetic transformation of cereals largely depends on the ability of transformed tissues to proliferate and subsequently to regenerate into whole plants. The plant tissue culture provides innovative technique for the development of crop varieties having desirable traits.

The application of many biotechnological methods in wheat improvement involves the development of a reliable in vitro plant regeneration procedure in a range of genotypes in order to induce a successful genetic transformation. Genetic transformation of wheat has been achieved by using immature embryo-derived calli as explant tissue (Wu et al., 2003). In general, the application of biotechnological techniques depends on the callus formation and the shoot regeneration capacity. Although immature embryos are widely recognized as the most suitable explants to regenerate wheat plants (Ozias-Akins and Vasil, 1982; Redway et al., 1990), environmental conditions influencing the physical status of field grown donor plants from which embryos were collected could be a limiting factor of their quality. Embryogenic competence of immature wheat embryo is lower when donor plants are exposed to some kind of stress. There were several attempts to replace immature embryos with other explant sources.

Many elements affect wheat regeneration, such as explant source (Ozias-Akins and Vasil, 1982), growth condition of donor plant, culture medium (Fennel et al., 1996), and genotype (Sears and Deckard, 1982), among which genotype is often the dominant one (Sahrawat et al., 2003). It is commonly regarded that immature embryo (Maddock 1985; Moon et al., 2003) is the best explant source for tissue culture among all explants, including inflorescence (Sharma et al., 1995), seeds (Gosch-Wackerle et al., 1979), immature leaves (Zamora and Scott, 1983), mature embryos (Ozias-Akins and Vasil, 1983), and sliced mature embryo fragments (Kim et al., 2005). The calli derived from alternative explants displayed a lower regeneration potential than those obtained from immature embryos, which are still a choice of different explants for establishing high regenerative wheat tissue.

We have a rather simple way to predict the outcome of tissue culture in advance, avoiding the need to test large number of genotypes at the tissue culture step, which is very expensive, laborious and time consuming. This study was conducted to predict the suitable embryos for an efficient

${ }^{\dagger}$ Corresponding author: (Phone) +82-2-2260-3307 (E-mail) bmlee@dongguk.edu

$<$ Received 1 September 2011; Revised 15 September 2011; Accepted 17 September 2011> 
regeneration system and to evaluate spring and winter wheat genotypes for plant regeneration. The embryo size and regeneration efficiency at different developmental stages were examined in spring and winter wheat genotypes.

\section{MATERIALS AND METHODS}

\section{Plant materials}

Ten genotypes of wheat, Milyang30, Sinjungjang, Sotaek, Jeokpijeok, Heongtaek, Jaseonlho, Igagihu, Kiok27, Geumgangmil and Bobwhite, were used. The mature seeds of each genotype were measured for seed weight, embryo length and width. And thirty immature embryos of each genotype were isolated at 9-10, 13-14, 17-18 and 21-22 days after anthesis (DAA).

\section{In vitro culture}

Milk stage wheat kernels were harvested and stored in a refrigerator at $4{ }^{\circ} \mathrm{C}$ for $24 \mathrm{~h}$. Individual immature caryopses were surface sterilized by washing in $70 \% \mathrm{EtOH}$ for 1 min, rinsed with sterile water and then vigorous wash with $40 \%$ Clorox containing 2 3 drops of Tween 20 for $20 \mathrm{~min}$. Subsequently grains were rinsed 3 times with sterile distilled water. The immature embryos were aseptically dissected from the sterile immature seeds with tweezers and scalpel under a dissecting microscope. The immature embryos of $0.5-2.0 \mathrm{~mm}$ in size were isolated and inoculated onto the induction medium in the dark at $25^{\circ} \mathrm{C}$ with embryo scutellum facing up.

\section{Callus induction and plant regeneration with immature embryos}

Wheat immature embryos were cultured on the callus induction medium (Table 1, CI) and the plates were incubated in the dark at $25^{\circ} \mathrm{C}$. Calli were transferred at two weeks intervals to fresh induction medium. The callus induction frequency was assessed at 4-5 weeks after culture establishment. Embryogenic capacity was then assessed by counting the number of explants with embryogenic callus present (the percentage of forming calli / number of immature embryos plated). After 4-5 weeks of incubation, calli were transferred to regeneration medium (Table 1, RM). Regeneration plates were incubated under the $16 / 8 \mathrm{~h}$ (light/dark) photoperiod at $25^{\circ} \mathrm{C}$ for $2-3$ weeks. Regeneration capacity was assessed
Table 1. Media composition for tissue culture of spring and winter wheat.

\begin{tabular}{lcc}
\hline \hline \multicolumn{1}{c}{ Composition } & CIM(/L) & RM(/L) \\
\hline MS salts & $4.4 \mathrm{~g}$ & - \\
MS salts \& B5 vitamins & - & $4.3 \mathrm{~g}$ \\
Sucrose & $30 \mathrm{~g}$ & - \\
Maltose & - & $30 \mathrm{~g}$ \\
Asparagine & $100 \mathrm{mg}$ & - \\
Glutamine & $500 \mathrm{mg}$ & - \\
Proline & $100 \mathrm{mg}$ & - \\
Phytoagar & $7 \mathrm{~g}$ & $7 \mathrm{~g}$ \\
\hline \multicolumn{4}{c}{$\mathrm{pH}$ adjusted to 5.7 then autoclave } \\
\hline 2,4-D & $2.0 \mathrm{mg}$ & $0.1 \mathrm{mg}$ \\
Picloram & $2.2 \mathrm{mg}$ & - \\
Zeatin & - & $5.0 \mathrm{mg}$ \\
\hline
\end{tabular}

as the number of callus producing shoots at the end of the 6-8 weeks of culture and referred as regeneration frequency. Data was analyzed via InStat (version 4, 2005).

\section{RESULTS AND DISCUSSION}

\section{Embryo size and seed weight of mature seeds}

The embryo length and width from mature seeds of spring and winter wheat genotypes were measured (Table 2). Milyang30, Jeokpijeok and Heongtaek had large embryo size and Geumgangmil and Jeokpijeok showed heavy seed weight. This appears that the embryo size and seed weight are not correlated with each other. Furthermore, immature embryo size of developing seeds did not show any significant difference in spring and winter wheat genotypes. Immature embryo length at 9-10, 13-14, 17-18 and 21-22 DAA was $0.5-1.0,1.0-1.2,1.2-1.5$ and $1.5-2.0 \mathrm{~mm}$, respectively. Several reports are signified the superiority of large seeds over small seeds with respect to germination rate, seedling emergence and growth (Lowe and Ries 1973; Aiken and Springer 1995; Smart and Moser 1999).

\section{Effects of age and size of immature embryos on callus induction}

The percentages of embryogenic callus for each genotype on callus induction medium were summarized in Table 3. 
Table 2. The embryo size and seed weight from mature seeds of spring and winter wheat.

\begin{tabular}{|c|c|c|c|}
\hline Genotype & Embryo length (mm) & Embryo width (mm) & Seed weight (g/1000 seeds) \\
\hline Milyang30 & 2.5 & 1.7 & 41.1 \\
\hline Igagihu & 2.1 & 1.4 & 28.9 \\
\hline Kiok27 & 2.1 & 1.6 & 39.7 \\
\hline Geumgangmil & 2.1 & 1.6 & 53.8 \\
\hline Bobwhite & 1.2 & 1.3 & 42.2 \\
\hline Sinjungjang & 2.3 & 1.5 & 29.5 \\
\hline Sotaek & 2.3 & 1.5 & 34.3 \\
\hline Jeokpijeok & 2.6 & 1.8 & 49.8 \\
\hline Heongtaek & 2.6 & 1.7 & 40.2 \\
\hline Jaseon1ho & 2.0 & 1.4 & 37.7 \\
\hline
\end{tabular}

Table 3. Percentage of callus induction during seed development of spring and winter wheat with standard error in parenthesis.

\begin{tabular}{|c|c|c|c|c|c|}
\hline \multirow{2}{*}{\multicolumn{2}{|c|}{ Genotype }} & \multicolumn{4}{|c|}{ Days after anthesis (DAA) } \\
\hline & & $9 \sim 10$ DAA & 13 14 DAA & 17 18 DAA & 21 22 DAA \\
\hline \multirow{5}{*}{ Spring wheat } & Milyang30 & $69.0(0.58)$ & $92.0(1.73)^{* * *}$ & $90.6(0.33)^{* * *}$ & $86.3(1.20)^{* *}$ \\
\hline & Igagihu & $69.0(2.31)$ & $90.7(0.67)^{* * *}$ & $87.3(1.76)^{* *}$ & $73.0(0.58)$ \\
\hline & Kiok27 & $68.7(1.86)$ & $83.7(2.73)^{* *}$ & $85.7(2.60)^{* *}$ & $54.0(2.31)$ \\
\hline & Geumgangmil & $63.0(2.89)$ & $96.0(1.16)^{* * *}$ & $93.0(0.58)^{* * *}$ & $80.3(1.45)^{*}$ \\
\hline & Bobwhite & $82.0(2.31)^{*}$ & $92.7(0.88)^{* * *}$ & $90.0(1.16)^{* * *}$ & $80.3(1.45)^{*}$ \\
\hline \multirow{5}{*}{ Winter wheat } & Sinjungjang & $64.7(1.86)$ & $86.7(2.03)^{* *}$ & $80.0(1.16)^{*}$ & $60.3(1.76)$ \\
\hline & Sotaek & $64.0(0.00)$ & $95.0(0.00)^{* * *}$ & $93.0(1.73)^{* * *}$ & $91.3(5.13)^{* * *}$ \\
\hline & Jeokpijeok & $82.3(2.40)^{*}$ & $90.0(0.58)^{* * *}$ & $88.0(2.00)^{* *}$ & $70.0(4.62)$ \\
\hline & Hoengtaek & $84.3(1.76)^{* *}$ & $91.0(1.16)^{* * *}$ & $87.3(1.67)^{* *}$ & $80.7(2.03)^{*}$ \\
\hline & Jaseon1ho & $64.3(5.24)$ & $92.0(0.58)^{* * *}$ & $91.0(0.58)^{* * *}$ & $82.3(2.96)^{*}$ \\
\hline
\end{tabular}

In seeds between 9 and 10 DAA, embryos from most genotypes tended to form watery and creamy calli and callus capacity was lower than between 13 and 22 DAA. In general, two types of calli were observed between 2 and 3 weeks. Non-embryogenic calli were characterized by a soft watery texture and creamy color, whereas embryogenic calli were compact, white-yellow and nodular. Except for between 9 and 10 DAA, which produced non-embryogenic calli, all other developing seeds induced embryogenic calli. It was found that the best developmental stage for callus efficiency is between 13 to 18 DAA and most of genotypes in spring and winter wheat were significant differences (Table 3). Especially, five genotypes, Milyang30, Geumgangmil, Bobwhite, Sotaek, and Jaseon1ho showed high levels of callus induction at $92 \%, 96 \%, 92.7 \%, 95 \%$, and $92 \%$, respectively, between 13 and 14 DAA. For spring wheat genotypes, the highest embryogenic capacity was obtained with immature embryo size between 1.0 and $1.5 \mathrm{~mm}$, and decreased when embryo size was smaller than $1.0 \mathrm{~mm}$ and bigger than $1.5 \mathrm{~mm}$. Only Kiok27 showed lower rate of embryogenesis than four spring genotypes.

\section{Effects of age and size of immature embryos on regeneration}

The regeneration frequency of spring and winter wheat varieties is indicated in Table 4. Regeneration is also dependent on age and size of immature embryos in wheat varieties. For regeneration frequency from developing seed, Bobwhite was highest at 13-14 DAA (77.7\%), whereas most of winter wheat genotypes was highest at 17-18 DAA 
Table 4. Percentage of regeneration during seed development of spring and winter wheat with standard error in parenthesis.

\begin{tabular}{|c|c|c|c|c|c|}
\hline \multirow{2}{*}{\multicolumn{2}{|c|}{ Genotype }} & \multicolumn{4}{|c|}{ Days after anthesis (DAA) } \\
\hline & & $9 \sim 10$ DAA & $13 \sim 14$ DAA & $17 \sim 18$ DAA & $21 \sim 22$ DAA \\
\hline \multirow{3}{*}{ Spring wheat } & Milyang30 & $29.0(0.58)$ & $61.0(1.56)^{* *}$ & $45.0(0.58)^{*}$ & $39.7(0.88)$ \\
\hline & Kiok27 & $50.3(1.20)^{*}$ & $74.0(0.58)^{* * *}$ & $69.3(0.88)^{* * *}$ & $20.0(3.51)$ \\
\hline & Geumgangmil & $51.0(1.73)$ & $69.0(0.16)^{* * *}$ & $62.7(2.60)^{* *}$ & $39.0(8.54)$ \\
\hline \multirow{4}{*}{ Winter wheat } & Sinjungjang & $37.0(2.08)$ & $52.3(1.33)^{*}$ & $53.0(3.22)^{*}$ & $39.0(0.00)$ \\
\hline & Sotaek & $56.7(4.26)^{*}$ & $67.0(5.69)^{* *}$ & $60.0(3.01)^{* *}$ & $42.0(0.58)$ \\
\hline & Jeokpijeok & $20.0(2.65)$ & $27.3(1.86)$ & $32.0(4.04)$ & $17.7(2.03)$ \\
\hline & Hoengtaek & $13.0(0.58)$ & $35.0(1.56)$ & $55.0(0.58)^{*}$ & $15.0(2.31)$ \\
\hline
\end{tabular}

*, ** and *** represent $\mathrm{P}$ values significant at $\mathrm{P}<0.05,0.01$ and 0.001 , respectively.

except Sotaek (13-14 DAA; 67\%). And regeneration efficiency was declined after 21 DAA for all genotypes, and differences between spring and winter wheat genotypes were not significant at 21-22 DAA. However, for the spring genotype, Milyang 30, the smallest embryos $(0.5-1.0 \mathrm{~mm})$ yielded the poorest regeneration, and for the winter wheat genotypes, Jeokpijeok and Heongtaek, the smallest embryos (0.5-1.0 $\mathrm{mm})$ and the largest embryos $(1.5-2.0 \mathrm{~mm})$ gave the lowest regeneration frequencies. All size of embryos can be cultured successfully provided a minimum developmental stage has been reached, generally between 13 and 14 DAA, or about $1.0-1.5 \mathrm{~mm}$ in embryo length.

An efficient and reproducible procedure for the regeneration of plants from tissue culture is a prerequisite for the application of gene transfer methods in crop improvement. A routine in vitro regeneration system has recently become available in hexaploid wheat and applied in genetic transformation by the introduction of alien genes. However, current systems for maintaining and subsequently regenerating plants from callus in durums are limited (Özgen et al., 1996). This study indicates that it is necessary for wheat immature embryos to reach a certain minimum age and size before they can be cultured successfully, in general at least 13 DAA and embryo length of at least $1.0 \mathrm{~mm}$. However, different genotypes produce embryos of different sizes and develop at different rates so the optimal age and size is likely to vary with the spring and winter wheat genotypes.
The developmental stage and size of embryos affect the somatic embryogenesis in wheat. This suggests that the developmental state of wheat immature embryos is critical for efficient somatic embryogenesis. Wheat immature embryos from the spikes harvested at developmental stage I $(<13$ DAA), II (12-15 DAA), and III (15-17 DAA) were better than those harvested at stage IV (16-24 DAA) or V $(>22$ DAA) for the induction of embryogenic callus in common wheat genotypes (He et al., 1988). In this experiment, the optimum developmental stage and embryo length for regeneration efficiency were at 13-14 DAA and 1.0-1.5 mm, respectively.

\section{ACKNOWLEDGEMENT}

This work was conducted with the support of the Cooperative Research Program for Agriculture Science \& Technology Development (Project No. 20110401-030-612-001-03-00 (PJ907047)), Rural Development Administration, Republic of Korea.

\section{REFERENCES}

Aiken, G. E. and T. L. Springer. 1995. Seed size distribution, germination, and emergence of 6 switchgrass cultivars. Journal of Range Management. 48 : 455-458.

Fennel, S., N. Bohorova, M. Ginkel, J. Crossa and D. A. Hoisington. 1996. Plant regeneration from immature embryos 
of 48 elite CIMMYT bread wheat. Theoretical and Applied Genetics. 92 : 163-169.

Gosch-Wackerle, G., L. Avivi and E. Galun. 1979. Induction, culture and differentiation of callus from immature rachis, seeds and embryos of Triticum. Zeitschrift Fur Pflanzenphysiologie. 91 : 267-278.

He, D. G., Y. M. Yang and K. J. Scott. 1988. A comparison of scutellum callus and epiblast callus induction in wheat: the effect of genotypes, embryo age and medium. Plant Science. $57: 225-233$.

Kim, K. H., M. S. Kang, Y. U. Kwon, S. K. Lee, J. H. Moon, S. Han, P. R. Oh and B. M. Lee. 2005. Plant regeneration from sliced mature embryo gragments of wheat cultivars. Korean Journal of Crop Science. 50 : 356-360.

Lowe, L. B. and S. K. Ries. 1973. Endosperm protein of wheat seed as a determinant of seedling growth. Plant Physiology. 51 : 57-60.

Maddock, S. E. 1985. Cell culture, somatic embryogenesis, and regeneration in wheat, barley, oats, rye, and triticales. In: Bright SWJ, Jones MGK (eds) Cereal tissue and cell culture. Nijhoff/Junk, Dordrecht. pp. 131-174.

Moon, J. H., S. K. Lee, K. H. Kim, M. S. Kang, H. Y. Heo, Y. U. Kwon, J. H. Nam, Y. W. Seo and B. M. Lee. 2003. Efficient callus induction and plant regeneration from immature and mature embryo culture of Korean wheat genotypes. Korean Journal of Crop Science. 48 : 38-43.

Özgen, M., S. Türet, S. Özcan and C. Sancak. 1996. Callus induction and plant regeneration from immature and mature embryos of winter durum wheat genotypes. Plant Breeding. $115: 455-458$.
Ozias-Akins, P. and I. K. Vasil. 1982. Plant regeneration from cultured immature embryos and inflorescences of Triticum aestivum (wheat): evidence for somatic embryogenesis. Protolpasm. 110 : 95-105.

Ozias-Akins, P. and I. K. Vasil. 1983. Improved efficiency and normalization of somatic embryogenesis in Triticum aestivum (wheat). Protoplasm. $117:$ 40-44.

Redway, F. A., V. Vasil, D. Lu and I. K. Vasil. 1990. Identification of callus types for long-term maintenance and regeneration from commercial cultures of wheat (Triticum aestivum L.). Theoretical and Applied Genetics. 79 : 588-596.

Sahrawat, A., D. Becker, S. Lutticke and H. Lorz. 2003. Genetic improvement of wheat via alien gene transfer, an assessment. Plant Science. 165 : 1147-1168.

Sears, R. G. and E. L. Deckard. 1982. Tissue culture variability in wheat: callus induction and plant regeneration. Crop Science. 22 : 546-550.

Sharma, V. K., A. Rao, A. Varshney and S. L. Kothari. 1995. Comparison of developmental stages of inflorescence for high frequency plant regeneration in Triticum aestivum L. and Triticum durum L. Desf. Plant Cell Report. 5 : 227-231.

Smart, A. J. and L. E. Moser. 1999. Switchgrass seedling development as affected by seed by seed size. Agronomy Journal. 91 : 335-338.

Wu, B. H., Y. L. Zheng, D. C. Liu and Y. H. Zhou. 2003. Trait correlation of immature embryo culture in bread wheat. Plant Breed. 122 : 47-51.

Zamora, A. B. and K. J. Scott. 1983. Callus formation and plant regeneration from wheat leaves. Plant Science Letter. 29 : 183-189. 